\title{
Does Justification Aim at Truth?
}

\author{
PETER J. GRAHAM \\ University of California, Riverside \\ Riverside, CA 92521 \\ USA
}

Does epistemic justification aim at truth? The vast majority of epistemologists instinctively answer 'Yes'; it's the textbook response. Joseph Cruz and John Pollock surprisingly say no. In 'The Chimerical Appeal of Epistemic Externalism' they argue that justification bears no interesting connection to truth; justification does not even aim at truth. 'Truth is not a very interesting part of our best understanding' of justification (C\&P 2004, 137); it has no 'connection to the truth.' A 'truth-aimed ... epistemology is not entitled to carry the day' (C\&P 2004, 138, emphasis added).

Pollock and Cruz's argument for this surprising conclusion is of general interest for it is 'out of step with a very common view on the part of epistemologists, both internalist and externalist alike' (C\&P 2004, 136), as nearly all 'epistemologists have claimed that truth and falsity play a crucial role in distinguishing between justified and unjustified beliefs [for] believing truths is the ultimate aim of human rational cognition' (C\&P 2004, 125; cf. Audi 1988).

I shall show their argument falls short. Though they purport to show that justification does not aim at promoting truth and avoiding error, and in so doing supposedly reveal that externalism's appeal is but 'chimerical,' all they actually show is that one version of externalism won't do. I will even show that a view they are well known for opposing the view they call 'norm externalism' - is a view they can, and should, embrace. In so doing I shall sketch an account where justification 
functions so as to promote truth and avoid error. Justification aims at truth, and they should think so too.

The interest of the present paper lies not simply in the refutation of Pollock and Cruz's argument. For their confidence that justification does not aim at truth derives not only from their rejection of traditional reliabilism, but also from the widely shared conviction that the traditional reliabilist has the upper hand when it comes to connecting justification and truth, a conviction that I shall critically examine. Furthermore, their confidence does not merely derive from this argument, but from the general tenor of Pollock's naturalist epistemology, where epistemology is continuous with the cognitive and evolutionary sciences. Their argument is, in a way, an expression of Pollock and Cruz's inability to find a place for truth in their naturalist research project. If the account I sketch is on the right track, then I shall have found a place for truth in their epistemology. And so my paper has four aims: to undermine Pollock and Cruz's argument; to critically examine the conviction that the traditional reliabilist best connects justification with truth; to sketch an alternative where justification aims at truth; and to find a place for truth in Pollock and Cruz's epistemology.

Before turning to their argument, I'll first characterize how Pollock and Cruz understand justification.

For Pollock and Cruz, justification is first and foremost a procedural notion, where a belief is justified iff formed or sustained by rational procedures of belief-formation. Being justified has to do with how beliefs are formed and sustained (Pollock 1999, 385-6; P\&C 1999, 14-15). Some beliefs are formed in ways that justify those beliefs; some are not. Justified beliefs result from following the correct rational (or good cognitive) procedures; unjustified beliefs result from incorrect procedures. ${ }^{1}$

Ordinary deductive or good inductive reasoning provide good examples of beliefs based on rational procedures. Suppose Susan believes $P$

1 Though procedural rationality may be necessary for knowledge, Pollock and Cruz do not see procedural justification along with true belief as sufficient for knowledge. Since having been formed or sustained by rational procedures provides no immunity to error or even to being right by accident, the procedural notion of justification does not capture what converts true belief into knowledge. As Gettier made clear, justified true belief may fall short of knowledge. In Gettier's cases, the subject's beliefs were formed or sustained on the basis of good rational procedures. And so for Pollock and Cruz, the explication of procedural justification is one thing, and the explication of knowledge is another (P\&C 1999, 11\&14). 
and if $P$ then $Q$, and then infers $Q$ on the basis of those beliefs and sensitivity to modus ponens. She formed the belief that $Q$ in a correct or rational way. Paradigmatically, rational belief formation preserves truth. If your premises are true, and you reason in a rational way, then your conclusions are (likely) to be true as well.

Pollock and Cruz - like many other moderate internalist foundationalists - extend this way of seeing justification to perceptual justification. A perceptual representation normally leads to perceptual belief. The normal transition from perception to belief is a rational (or good cognitive) procedure. Pollock and Cruz even use 'reason' broadly, and call the perceptual representation - the percept $-\mathrm{a}$ reason. The transition from percept to belief is thus a case of reasoning, broadly construed (P\&C 1999, 88, 123). The parallel with ordinary reasoning is then straightforward. If your perception is accurate, then the appropriately or rationally derived perceptual belief will be accurate too. Beliefs from reasoning as well as perception result from following rational procedures.

Paradigm externalists do not object to this procedural conception of justification, and neither do I. Goldman (1986) would call this property 'justifiedness' and Burge (1993) would call it 'warrant,' distinguishing in turn two types of warrant: justification and entitlement. For ease of discussion I will stick to Pollock and Cruz's terminology.

Like Pollock and Cruz, I will also largely restrict my focus to empirical, perceptual justification (P\&C 1999, 15). Perceptual justification may importantly differ from other kinds or sources of justification or warrant. Though the discussion will move back and forth between perceptual justification as a particular case and justification in general, for the most part my talk of justification throughout should be understood as restricted to perceptual justification.

This takes us to their understanding of internalism. One traditional way of defining internalism involves the subject's reflective access to internal mental states that serve as the subject's reasons or evidence in an argument or explanation supporting the target belief. This internalist sees justification as residing in these arguments; being justified is thus a significant intellectual achievement. Externalists reject this conception. So do Pollock and Cruz (P\&C 1999, 136-7). For Pollock and Cruz, justification or warrant does not consist in justifications - in arguments possessed by the justified individual. Even so, Pollock and Cruz are still internalists for two interrelated reasons.

First, when explicitly stated, the correct procedures refer only to internal mental states, events, and processes. Pollock and Cruz call these internal procedures 'epistemic norms' (P\&C 1999, 25). Here are two formulations of such a norm for perceptual belief: 'Having a percept at time $t$ with the content $P$ is a defeasible [justifier] for the cognizer 
to believe P-at-t' (P\&C 1999, 201). Or, 'If a person has a clear sensory impression that $\mathrm{x}$ is $\mathrm{F}$ (or of $\mathrm{x}^{\prime} \mathrm{s}$ being $\mathrm{F}$ ) and on that basis believes that x is F, then this belief is prima facie justified' (Audi 2001, 43). One psychological state internal to the subject's mind - a percept or sensory impression - provides epistemic support for a belief - another state inside a subject's mind. Relying on the percept or impression constitutes good cognition or rational belief-formation. Justification is at least a mind-mind relation. Second, for Pollock and Cruz no external connection with truth - no objective fit with the facts - makes a difference to which norms are true. Perceptual justification bears no interesting or essential connection to getting things right (P\&C 1999, 113-15). They call this 'norm internalism.'

The opposing 'norm externalist' view holds that the content of epistemic norms involves internal states, but go on to hold that what distinguishes epistemic from non-epistemic norms involves some substantive connection with fitting the facts, with objectively getting things right. Justification is also a mind-world relation (cf. Burge 2010, 50-1). As Pollock and Cruz put it, 'norm externalism...p proposes that alternative sets of internalist norms should be evaluated in terms of external considerations. The premiere external consideration is ... truth-aimedness' (C\&P 2004). 'Norm externalists think that being aimed at the truth is the criterion of correctness for epistemic norms' (C\&P 2004, 135; P\&C 1999, 137-9; Alston 1985; Goldman 1986). But since justification does not aim at truth, norm externalism cannot be correct. Or so they argue.

II

Pollock and Cruz hold that justification in general, and perceptual justification in particular, does not aim at truth. I present their argument in two stages. Here is the first:

(P1) A belief's being justified is a function of the intrinsic, inherent, essential nature of the internal, psychological process(es) that causes or sustains it.

(P2) Whether an internal, psychological process produces true beliefs or not in the circumstances of use (whether it actually results in true beliefs more often than not, whether the process is de facto reliable) is an extrinsic, non-inherent, inessential feature of the process.

(C1) Hence justification (following correct procedures) is independent of (whether those procedures) actually resulting in true beliefs for the most part. 
Here are two supporting passages:

We maintain ... that the justifiability of a belief is exclusively a function of internal [cognitive, mental, psychological] states, where internal simply means inside an agent's cognitive apparatus [mind]. What this means is that we can vary everything about the situation other than an epistemic agent's internal [mental, psychological] states without effecting which of her beliefs are justifiable. In particular, varying contingent [non-psychological] properties such as the [de facto] reliability of the cognitive processes that produce or sustain a belief will not affect whether that belief is justified. We have called this cognitive essentialism. According to cognitive essentialism, the epistemic correctness of a cognitive process is an essential and inherent feature of that process. (C\&P 2004, 127, emphasis added; see also P\&C 1999, 25)

... intuitively, it is not the extrinsic properties of the process that generate a belief that is responsible for its justifiedness. The intuition has been the source of repeated attempts by internalists to generate cases to show that... reliability is neither necessary nor sufficient for justification. (C\&P 2004, 130; see also P\&C 1999, 113)

They think the massively deceived brain-in-a-vat and accidental reliability (clairvoyant power) cases support (P1) and (P2) (P\&C 1999, 113$14)$; these are the cases 'generated by internalists.'

In the brain-in-a-vat case, in the actual circumstance an ordinary human forms beliefs reliably on the basis of perception. Then in the counterfactual case, the same human, relying on the very same perceptual process, unknowingly forms mostly false beliefs, having been envatted and hooked up to a massive supercomputer by a deceptive scientist. Intuitively the psychological procedure remains the same. Intuitively the beliefs are justified in both the actual and counterfactual cases. Because justification persists as reliability lapses, justification conferring seems to be an 'intrinsic' or 'essential' feature of the process, but matter of fact reliability seems to be 'extrinsic' or 'inessential.' Hence (P1), (P2) and thus (C1).

The clairvoyant powers case is supposed to work similarly, but in the opposite direction. A random mutation causes an individual to acquire a power that reliably induces true beliefs about some subject matter, where the individual knows nothing about the mutation. Supposedly the beliefs caused lack justification, despite the 'extrinsic' reliability of the power.

Some may contest these cases; perhaps they don't really support the first stage of the argument. I shall not. I agree that de facto reliability - reliability in the circumstances of use - is neither necessary nor sufficient for justification. I accept the cases. ${ }^{2}$ De facto reliability doesn't

2 Actually, since there are interesting variations on the cases, I do not accept the cases without qualification. For discussion, see my 'Epistemic Entitlement.' 
connect belief with truth the way justification does; de facto reliability isn't the right connection between justification and truth.

Here is the second stage, building on (C1):

(C1) Justification (following correct procedures) is independent of (whether following those procedures) actually resulting in true beliefs for the most part.

(P3) Justification (following correct procedures) aims at truth if an only if justification (following those procedures) in the actual circumstances of belief-formation results in true beliefs for the most part.

(C2) Hence justification does not aim at truth. (C1, P3)

Pollock and Cruz clearly embrace (P3): 'Properties of epistemic agents that are truth-aimed [include] the actual reliability of their cognitive processes' (C\&P 2004, 125). They attribute the logic behind (P3) to the externalist:

Since truth has been viewed as the ultimate epistemic aim, externalists have attempted to answer to that aim directly by making it a non-negotiable constraint on a theory of justification that whatever justification is will co-vary in some way with truth. (C\&P 2004, 126)

Such reasoning is commonplace among reliabilists. Witness Charles Landesman:

The aim of...justification is to arrive at truth, so a [process] of fixing belief that can be counted on to provide truth more often than not succeeds in providing... justification. $(2002,115)$

Landesman asserts sufficiency; the spirit suggests necessity. Regardless, the idea here is that justification aims at truth if and only if it achieves truth more often than not. And that is just (P3). Reliabilists identify aiming at truth with reliably achieving it; Pollock and Cruz have bought into the identification.

Pollock and Cruz correctly point out that 'aim' is best taken metaphorically. For belief-forming processes, unlike persons, do not literally aim at anything. (P3) is their way of cashing out the metaphor, the way traditional reliabilists do.

Returning to the argument, we now have a case where one person's modus ponens is another's modus tollens. Pollock and Cruz, on the one hand, and the reliabilist, on the other, both accept (P3). Pollock and Cruz reason from the premise that perceptual justification does not turn on de facto reliability to the conclusion that perceptual justi- 
fication does not aim at truth. The (simple, de facto) reliabilist, on the other hand, reasons from the premise that perceptual justification aims at truth to reach the conclusion that perceptual justification consists in de facto reliability.

It looks like we have a forced choice: either justification in general and perceptual justification in particular aims at truth and the de facto reliability theory is true, or the de facto reliability theory is false and justification does not aim at truth. Pollock and Cruz's argument, in a nutshell, is the latter horn of the dilemma.

This is a false dilemma. I accept that justification aims at truth, but not that justification turns on de facto reliability. Aiming at truth is one thing, actually achieving it is another. Justification can be understood in terms of promoting truth and avoiding error, in terms of objectively fitting the subject-matter of belief, even though justification does not simply co-vary with getting things right. Or so I will argue.

I shall first show that three familiar arguments for (P3) from traditional reliabilists don't work. Both Pollock and Cruz on the one hand, and the reliabilist on the other, will be left without an argument for (P3); the dilemma falls apart. Then I'll sketch an account where perceptual justification aims at truth, but doesn't turn on de facto reliability. There's another way to cash out the metaphor open to the norm externalist. I'll go on to explain why Pollock and Cruz can and should accept such an account. Not only do they not have a good reason for thinking justification does not aim at truth, they have reason for thinking it does.

\section{III}

In this section I criticize three arguments for (P3), read generally. In each case I shall lean on our non-metaphorical understanding of aims to pressure the putative connection between 'aiming' at something and achieving it.

Here is the first familiar argument for (P3):

(a) To aim at an end is to produce or achieve it more often than not.

Hence, justification aims at truth (the correct procedures are tied to objectively fitting the world) if and only if justification (following the correct procedures) actually produces true beliefs more often than not in the circumstances of use.

This argument, though valid, is clearly not sound. Premise (a) is not unrestrictedly true. You can aim at all sorts of things and hardly ever achieve them. Think of dieting. If only aiming at something were the same as reliably achieving it. 
Other arguments in the ballpark from reliability theorists fare no better. Here is Frederick Schmitt:

Justified belief [is tied] to true belief [because justified belief] contributes to the end of true belief. (...) The idea that justified belief is belief that contributes to the end of true belief is most straightforwardly developed by identifying it with reliable beliefbelief of a sort that is generally true. (...) Exercising reliable processes is therefore indispensable for achieving the ... end of true belief. Reliabilism identifies justified belief with the means to [this] end. (1992, 2-3, emphasis added)

Schmitt's argument goes as follows:

(b) To contribute to an end is to produce the end more often than not.

(c) To aim at something just is to contribute to it.

Hence, justification aims at truth (the correct procedures are tied to objectively fitting the world) if and only if justification (following the correct procedures) actually produces true beliefs more often than not in the circumstances of use.

Cleary (b) and (c) are not unrestrictedly true. You can contribute to ends or goals but the end or goal is hardly ever achieved. Campaign contributions are a good example. You can aim at something without contributing to it; not all aims even get off the ground. And you can contribute to something without aiming at it. Accidents happen.

Here's a third argument that fares just as poorly:

(d) To conduce towards truth is to produce truth more often than not.

(e) To aim at something just is to conduce towards it.

Hence, justification aims at truth (the correct procedures are tied to objectively fitting the world) if and only if justification (following the correct procedures) actually produces true beliefs more often than not in the circumstances of use.

On the reading where (d) is true, (e) is false: if 'conduce' to an end really means to achieve the end, then you can make something happen without aiming at it, and you can aim at it without really making it happen. And the reading where (e) is true, (d) is false: if 'aim' means to take steps towards a goal, and if 'conduce' just means to take steps towards a goal, then you can conduce towards something without producing it; the steps taken may fall short.

Since you can aim at an end without producing it for the most part, (P3) is not supported by these arguments. Granting (C1) does not show 
that justification does not aim at truth. It is not analytic that justification aims at truth if and only if justification achieves, or actually results in, true belief for the most part. It is not even true. Aiming at something is one thing; actually achieving it is another. Neither Pollock and Cruz nor de facto reliability theorists have a good argument for (P3). ${ }^{3}$

If perceptual justification in particular does not aim at truth by actually achieving it for the most part - if de facto reliability isn't the only way to cash out the metaphor that justification aims at truth - then what would it be for perceptual justification to aim at truth? If what makes perceptual belief formation epistemically correct does not turn on the matter of fact reliability of perception, then could some other objective fit with the facts could account for perceptual justification?

In the next two sections I will sketch a 'norm externalist' account where justification aims at truth, where it turns on objectively fitting the facts, but not simply on matter of fact reliability in the circumstances of use. I will argue that justification is tied to the function of the beliefforming process. Perceptual justification aims at truth because perception has inducing true beliefs reliably as a function.

I won't fully defend the account; I'll provide only the bare bones. In just one paper I can't both engage Pollock and Cruz and establish a rival account of justification. The point instead is to offer one that shows just how (C1) might be true and (P3) might be false in a way that Pollock and Cruz can, and should, accept. A full out defense must take place elsewhere. ${ }^{4}$

3 There is another widespread argument in the literature for connecting justification with de facto reliability: (1) Knowledge is at least justified true belief, so justification, along with true belief, takes one (at least close) to knowledge; (2) Knowledge at least requires the de facto reliability of the belief-forming process; (3) So justification is, or supervenes upon, de facto reliability. The spirit of such an argument occurs throughout Goldman's writings (see his 1986), especially when arguing against internalists, and in Sosa's account of justification and knowledge (2003). Some authors even use 'justified' as shorthand for 'based on a de facto reliable belief forming process.' For those authors, it is analytic that the subject of the demon-world lacks justified beliefs. But unless we are stipulating such a use for 'justified,' such reasoning is clearly fallacious. Just because justification and de facto reliability are both necessary conditions on knowledge (if they are), it does not follow that the former just is, or supervenes upon, the latter. Cakes require eggs and flour, among other ingredients. But eggs and flour are, for all that, different things.

4 See my 'Epistemic Entitlement' as well as my 'Testimonial Entitlement and the Function of Comprehension.' 
IV

In one sense of 'function,' functions are purposes. The function of the heart is to pump blood. That is what it is supposed to do. That is what it is for. The heart's aim, speaking metaphorically, is to pump blood.

Functions determine natures. It's a part or an aspect of the nature of the heart to pump blood. What hearts are for contributes to what they are. So if a belief-forming system or procedure has forming true beliefs reliably as a function, then forming true beliefs reliably is constitutively associated with its nature.

An etiological function of an item is a selected effect of past tokens of the item (ancestors) that contributed to the existence of later tokens (descendants) of the item. Crudely, functions are selected effects. That our hearts ancestor's pumped blood explains why there are hearts now. Our hearts pumped blood in a way that was selected for against variants. Pumping blood that way conferred a selective advantage on our ancestors, and thereby explains (in part) why our hearts exist now. Pumping blood that way is thus an etiological function of our hearts. Our hearts are supposed to pump blood a particular way. And in so doing, they contribute to fitness, and the continued existence of hearts. An etiological function derives from the historical explanation of the selection, replication and persistence of the item. A pattern of relations to a broader environment fixes functions, and so contributes to natures. ${ }^{5}$

An explanatory account of normal conditions and normal functioning naturally falls out of the historical explanation (Millikan 1984). Normal functioning just is functioning (operating) the way ancestors worked - how they functioned - so as to produce the effect that explains why the item was selected. Normal conditions just are those conditions (and conditions relevantly similar) where all of this occurred. Ancestors produced an effect by working a certain way in certain conditions. By producing that effect by working that way in those conditions the item contributed to later occurrences of the very same item. Ancestors of our hearts pumped blood in our bodies on the surface of the Earth, and in

5 Other uses of 'function' involve how a system happens to work, what its causal role capacities are (what it can do), how it is supposed to work or operate (normal functioning), and what it was intentionally designed to do. I am aware of competing accounts of function ascription in biology and various non-historical accounts of functions. I am also aware of different kinds or sources of functions. See my 'Two Sources of Purpose and Plan' for some discussion.

The etiological account of functions derives from Larry Wright (1973), and then was developed (in different ways) by Ruth Millikan, Karen Neander, Peter Godfrey-Smith, and David Buller among others. Buller 1999 is a useful anthology of papers, which includes papers from critics as well as advocates. 
so doing contributed to survival long enough to reproduce and in so doing make new hearts. By working normally in normal conditions, ancestors of our hearts fulfilled what would become a function of the heart. Functional kinds thus partly supervene on explanatory histories. So if a belief-forming system has forming true beliefs reliably as an etiological function, it partly supervenes on its explanatory history. ${ }^{6}$

Ceteris paribus, items with etiological functions fulfill their functions when functioning normally in normal conditions. For if they did not they would not have those functions. ${ }^{7}$ Normal functioning is thereby partially understood and individuated in terms of function fulfillment. Normal functioning is thereby constitutively associated with function

6 I am aware of putative counterexamples to this account. A referee helpfully reminded me of one in particular. Here is a recipe for generating counterexamples that target the necessity of the account. At the first stage, stipulate that a creature has a belief-forming system 'relevantly like' ours. It either duplicates the form of our perceptual system, for example, or it causes similar effects as ours, e.g. reliably true beliefs. At the second stage, stipulate that the process lacks a history Swampman (a duplicate of a human created by freak accident out of the swamp, with no causal or explanatory connection to any actual human) will do the trick - or grant that the process has history, but stipulate that it has no etiological functions, or grant that it has functions, but deny that it has reliably inducing true beliefs as a function. Voila, 'intuitively' it has justified beliefs, but fails to meet the conditions I require.

I cannot pause here to critically discuss this recipe or any of the particular cases. I respond to some of them in detail elsewhere. In brief, I have a two-pronged reply. First, insofar as they target necessity, they do not show that normal functioning for a belief-forming process that has reliably inducing true beliefs as an etiological function is not sufficient for a kind of justification or warrant. The idea here is that since there is a plurality of warrants and other epistemic goods, it is no surprise that not all require selection for reliability. Some kinds may 'intuitively' pop out in the cases, without being the kind I have isolated. In the end, having been selected for reliability may be necessary for the one I've isolated. Second, I challenge the metaphysical stability of the cases. The idea here is that the two stages in the thought experiments pull in opposite directions. The more the procedures are 'relevantly like' ours in their natures, the less plausibly they lack the relevant explanatory history of selection for reliability.

7 Some items are selected for reliability vis-à-vis an effect, some are not. The function of sperm is to fertilize eggs. But sperm hardly ever do that, even in normal conditions, functioning as normally as can be. Sperm need only fertilize eggs often enough to confer a selective advantage, and so be selected for. And often enough, for sperm, is not very often. But at the other end of the spectrum some devices fulfill their functions all of the time when functioning normally in normal conditions. The heart provides a good illustration. It must pump blood all the time. Less reliable hearts were selected out. Functional items that were selected for high frequency of their functional effect have reliably producing that effect as their function. The heart is for reliably pumping blood. 
fulfillment (cf. Burge 2007, 1-2; 2010, 51-67). And since the function contributes to the nature of the item, normal functioning is constitutively associated with the nature of the item. That the item is supposed to work (operate, function) like this is constitutively tied to its nature.

Normal functioning functions so as to promote the fulfillment of the item's function; the items works the way it does in order to fulfill its function. Normal functioning thereby contributes to function fulfillment. In normal conditions it conduces towards function fulfillment. Normal functioning contributes to and conduces towards function fulfillment. Speaking metaphorically, normal functioning aims at function fulfillment. So speaking metaphorically, for any item with an etiological function, its function is its aim, and it aims at function fulfillment by functioning normally. Normal functioning 'aims at' fulfilling the item's function. Function fulfillment is the effect that normal functioning is working towards.

Despite the interconnection, normal functioning and function fulfillment differ. An item can function normally (it's not broken or malfunctioning) but not fulfill its function for it's not in normal conditions. You can take a healthy heart out of someone's chest during a long and complicated surgery and hook it up to a machine whereby it beats regularly without pumping blood. It functions normally - it's not diseased though it doesn't pump blood for it's not in normal conditions. It can function so as to pump blood without successfully pumping anything at all. It can beat in order to pump blood without pumping blood. It can aim at function fulfillment without achieving its aim. It can work towards function fulfillment without effecting function fulfillment.

Our perceptual belief-forming systems empirically have forming true beliefs reliably as a function. First, it is uncontroversial that our perceptual belief forming systems reliably induce true beliefs. Second, it is uncontroversial that our perceptual systems are adaptations; they are a paradigm case of complex design through natural selection. Third, given the obvious adaptive benefits of reliably representing one's physical environment, it's obvious that our perceptual systems and the transitions to perceptual belief were selected for reliably inducing true belief. (I shall return to this argument.) Our perceptual belief-forming system has forming true beliefs reliably as an etiological function. Getting things right is one thing human perception is for.

Normal functioning for perception is then constitutively associated with reliably producing true beliefs. Operating that way wouldn't be normal unless operating that way were objectively tied to fitting the facts. The procedure's nature depends on having contributed to reliably inducing true beliefs. Normal functioning thereby 'encodes' reliably inducing true beliefs. Normal functioning for perception is not only a mind-mind relation; normal functioning is also constitutively 
determined by mind-world relations. Normal functioning is operating in a way that aims at, contributes to, and conduces towards mostly true beliefs; normal functioning functions so as to reliably promote truth and avoid error.

\section{V}

I now use these ideas to explicate perceptual justification. I briefly argue that (prima facie) perceptual justification consists in the normal functioning of the perceptual belief-forming system for it has forming true beliefs reliably as an etiological function.

Functions determine norms or standards. An item with a function is supposed to fulfill its function. When the item fulfills it function, it meets a norm or standard set by its function.

What counts as normal functioning also determines a norm or a standard. Just as the heart is supposed to pump blood, the heart is also supposed to work or beat in a particular way. A normally functioning heart works the way it is supposed to. A malformed or dysfunctional heart does not. So when the item with an etiological function operates normally, it meets this second norm or standard constitutively associated with its function.

Meeting norms or standards is a good or success for the functional item. This is a broad use of 'good' and 'success.' It does not imply agency or intention. Nor is the good necessarily a moral good. So function fulfillment and normal functioning are goods, successes, or achievements constitutively associated with the item's function. Thus for any beliefforming process that has forming true beliefs reliably as an etiological function, there are (at least) two goods constitutively associated with reliably inducing true beliefs that follow from its function: function fulfillment and normal functioning.

Since justification may persist while reliability collapses - as in the case of the massively deceived brain-in-a-vat — function fulfillment is not required for perceptual justification.

Since normal functioning for our perceptual belief-forming systems is a good constitutively associated with reliably inducing true beliefs and avoiding errors, and since epistemic justification is a good or success understood in terms of promoting truth and avoiding error, but since perceptual justification does not entail de facto reliability, normal functioning for a process with getting things reliably correct as a function fits the bill. Justification consists in meeting norms constitutively associated with promoting truth and avoiding error. Normal functioning for a process with reliably inducing true beliefs as a function meets such a norm. I conclude that empirical, perceptual justification consists 
in normal functioning, for perception has forming true beliefs reliably as a function.

It's worth repeating how this account treats the brain-in-a-vat. Beliefs in brain-in-a-vat scenarios, though nearly entirely false, would still be justifiable, for the relevant belief-forming processes may still function normally even if not in normal conditions, like a healthy heart that is removed from a patient during surgery, or a mint condition car up on the rack during an inspection. Your perceptual system outside of normal conditions may still function normally. It may function so as to promote truth - it may function in order to reliably induce true beliefs - without producing any while in abnormal circumstances. Perceptual justification entails reliability in normal circumstances, but not reliability in present circumstances, for the individual may have strayed from normal conditions.

And accidentally acquired reliable belief-forming processes, like a clairvoyant power, would not justify beliefs, for such a process is not there because it produces true beliefs reliably. Producing true beliefs reliably would not be its function, and nothing would count as normal functioning for such a process. Such a process may cause true beliefs - and true belief may in itself be an epistemic good - but the process doesn't aim at truth, and doesn't justify the beliefs it causes and sustains.

With reliably inducing true belief as a function, normal functioning functions so as to promote reliably inducing true beliefs. Normal functioning then aims at reliable truth. Normal functioning contributes to reliably getting things right. And in normal conditions, normal functioning conduces towards true belief. Perceptual justification consists in normal functioning, and thereby aims at, contributes to, and conduces towards true belief. 'Truth and falsity play a crucial role in distinguishing between justified and unjustified belief because believing truths is the aim' of the belief-forming process (cp. C\&P 2004, 125). ${ }^{8}$

8 Besides not turning to God and the very different category of consciously intended design plans and purposes, it is here that my account clearly differs from Plantinga's (1993) related account. On his account, 'warrant' requires that the subject's belief-forming process not only operate according to the design plan, but the subject must also be in the conditions the designer had in mind. Pollock and Cruz rightly point out that this account of 'warrant,' were it also an account of justification, would run into trouble with brain-in-vat cases $(1999,121)$. The view presented here doesn't, for it doesn't require that the subject be in normal conditions for justification, only that his belief-forming processes function normally. I examine Plantinga's account in more detail, and Michael Bergmann's (2006) related account, elsewhere. Other norm externalist accounts include Burge (2003), Goldman (1986), and Sosa (2003). I critically examine Burge's account in 'Perceptual 
I have restricted my conclusions to perceptual justification. Perceptual justification is a kind of justification or warrant. There may be other kinds. And other processes of belief-formation may enjoy the same kind or source as perception, but only if they too have forming and sustaining true beliefs reliably as an etiological function. ${ }^{9}$

VI

In this section I shall argue that Pollock and Cruz can, and should, accept this account.

True, their main conclusion (C2) — 'justification does not aim at truth; truth is not the 'normative end' of justification' - is denied. So too is the crucial third premise shared by de facto reliabilists, (P3). However, their anti-reliabilist (C1) is embraced. (C1) is true, but (P3) and (C2) are not.

(P1) and (P2) are embraced as well. The 'correctness' of our perceptual systems is essential to them; it's associated with their natures. For correct procedures are standards for normal functioning for belief forming processes with reliably forming true beliefs as an etiological function. Normal functioning for such processes is constitutively associated with function fulfillment, and so with the function - and so an aspect or part of the nature or essence - of the belief-forming procedure; its connected to what the procedures are for, and so what they are. Standards for normal functioning are then 'inherent' or 'intrinsic' to the beliefforming process. Change in external circumstances after the function is set and stabilized does not affect the correctness of those procedures of belief-formation. The correctness of the procedures partly supervenes on their explanatory history of reliably getting things right.

I recognize the subtlety of this point. The idea is that the 'intrinsic' and 'essential' nature of the belief-forming procedures involves their explanatory histories. Internalists in both philosophy of mind and epistemology tend to take the natures of our mental states and cognitive procedures for granted without investigating how their natures are possible - how they are determined or fixed. They then inevitably discount constitutive associations between their natures and the broader, especially historical, formative environment. Like Descartes who was

Entitlement and Natural Norms.' I discuss some of Goldman's work in 'Epistemic Entitlement.' I intend to discuss Sosa's view on a future occasion.

9 To see how the present account might apply to so-called 'testimonial' justification, see my 'Testimonial Entitlement and the Function of Comprehension.' 
certain that he was a thinking thing but wasn't certain he had a body (and so whether he had a brain and a nervous system), internalists in the philosophy of mind and in epistemology rapidly conclude that the nature or essence of mind and mental processes does not constitutively depend on brains, bodies, relations to a broader environment, or an explanatory history. The nature is somehow exhaustively given to firstperson reflection. But if in fact our perceptual belief-forming procedures have forming true beliefs reliably as an etiological function, then getting things right in normal conditions when functioning normally is constitutively associated with the nature. Getting it right in normal conditions while functioning normally is then an 'intrinsic' and 'inherent' feature of perception, whereas getting it right in any old circumstance or other would be 'extrinsic' or 'non-inherent.' The natures of our perceptual systems - as so their epistemology — isn't simply exhaustively given or revealed by first-person reflection. The fact that natures are 'external,' however, is not at odds with cognitive essentialism, for 'externalism' isn't at odds with the very idea that cognitive systems have natures, and that their epistemology is 'intrinsic' and 'inherent' to them. So Pollock and Cruz can accept this account; it is consistent with their evidence and their 'cognitive essentialist' position.

And here is why they should. A standard objection to their view goes like this: if justification has nothing to do with truth, if 'truth is not a very interesting part of our best understanding' of justification, then why think that forming a belief in accord with a so-called 'epistemic' norm should count as epistemically justified? If 'belief formation is not aimed at truth, then' how would one distinguish 'epistemic reasons from non-epistemic reasons'? What is the difference between good cognition and cognition that falls short? What is the difference between epistemic procedures and non-epistemic procedures? Should any belief formed in accord with a subject's cognitive architecture count as justified? Pollock and Cruz seem to think so. But, as far as I can tell, hardly anyone else does.

Examples illustrate the point. Pollock and Cruz mention Plantinga's example of Paul, who 'suffers from a brain lesion induced by radioactive fallout from a Soviet missile test. He now reasons differently from the rest of us; when appeared to in the church-bell fashion, he forms the belief that something is appearing to him in that fashion, and that it is orange' (Plantinga 1993, 170). But, as many of us would say, his belief that it is orange is not justified. Even so, Pollock and Cruz demur, for Paul is 'reasoning according to his norms' (C\&P 2004, 135). On their view, wildly false beliefs based on bizarre mutations enjoy justification, provided that the mutation produces a new psychological process in the subject's psychology with a 'functional' input-output profile: internal state causes belief in a regular way. It looks like all we have to do is 
add some 'internal' prior state to any belief-forming process and come up with an epistemic norm. For instance, just add a bell-tone before a belief about where the President happens to be, and a clairvoyant power, reliable or not, now confers justification on beliefs about the President's whereabouts.

Nearly everyone else finds this view incredible. Not every 'internal norm' of belief-formation confers epistemic justification on beliefs soformed. Epistemology draws a distinction between epistemic and nonepistemic norms. Pollock and Cruz don't. Clearly they should. Since they can accept the view I have just sketched, where justification aims at truth and there is a shard contrast between epistemic and non-epistemic norms, they can and should find a place for truth in their procedural epistemology.

\section{VII}

But I am pretty sure, given everything I have said so far, that they won't accept the account I have sketched. We need to dig a little deeper.

I think their real opposition to norm externalism comes from their understanding of the place of 'reason' in nature. ${ }^{10}$ Pollock and Cruz

10 When Pollock and Cruz explicitly argue against norm externalism, they seem to have a version in mind that I do not hold. On the version they criticize, norm externalism is not simply the view that what makes epistemic norms true is the fact that they articulate the normal functioning of a belief forming process that has forming true beliefs reliably as a function, but rather the view that considerations of de facto reliably should lead us to revise our norms. "The norm externalist ... recommends[s] changes[s] in procedural norms on the basis of considerations of reliability' (P\&C 1999, 141). Norm externalists thus criticize and correct epistemic norms based on whether the processes are de facto reliable (P\&C 1999, 138-9, 142). So understood, norms externalism is not an account of the nature of justification, but part of a broader ameliorative, revisionary project. This project makes perfect sense when evaluation acquired and learned belief-forming methods, such as diagnostic techniques in hospital emergency rooms and sampling techniques in social science research. But does it make equally good sense when applied to our psychologically most basic processes of belief-formation, such as perception and rudimentary inductive reasoning? (Cf. Goldman 1986 on processes vs. methods.)

Pollock and Cruz argue that it does not:

Our epistemic norms are not subject to criticism in this way. Particular instances of reasoning are subject to such criticism, and the criticism can dictate changes in that reasoning, but this does not lead to changes in our epistemic norms. This is because unlike other norms, our epistemic norms already accommodate criticism based on reliability. The point is twofold. First, discovering that certain kinds of inferences are unreliable under certain cir- 
apparently think that the only 'naturalist' external evaluation of our belief forming processes, and so of our 'epistemic norms,' would involve practical success, not truth. From the point of view of evolutionary theory - a 'naturalistic' vantage point from which to 'evaluate' our inner psychologies - 'epistemic' norms are to be evaluated by their contribution to survival, and not by their contribution to truth. At best what makes procedures good is that they are survival enhancing, truth is irrelevant. So if we raise the question about what makes a procedure a good one, all we have to go on is its contribution to survival.

\section{Pollock and Cruz say}

... theories of human rationality describe ... human cognitive architecture ... evolutionary pressures select for traits that enhance survivability .... We might regard the design problem for rationality to be that of creating an agent that can survive ... by virtue of its cognitive capabilities ... . Epistemic cognition is, in an important sense, subservient to practical cognition. The principal function of cognition is to direct activity (practical cognition), and the role of epistemic cognition in rationality is to provide the factual background required for practical cognition ... . There is probably no privileged design goal in terms of which to evaluate cognitive architectures, and truth certainly does not recommend itself as the only consideration .... The ultimate objective of [cognition generally] is not truth, but practical success through the operation of epistemic norms. (C\&P 2004, 138-40, emphasis added)

They are here echoing their discussion from their 1999:

We can evaluate cognitive architectures in terms of how well they achieve their design goal. This is reminiscent of norm externalism's evaluation of epistemic norms in terms of reliability. But one big difference is that practical and epistemic cognition are evaluated as a package. The ultimate objective is not truth, but practical success. Still, it seems the production of true beliefs ought to be as least indirectly valuable

cumstances constitutes a defeater for those inferences and hence makes us unjustified in reasoning that way, and this is entirely accordance with our natural unmodified episteme norms. ... Second, discovering that some new inferences are reliable under certain circumstances provides us with justification for making those inferences under those circumstances, but this is licensed by the norms we already have. This is precisely what induction is all about. ... Our actual epistemic norms are self-correctly ... having the result that ... external criticism ... does not necessitate any modification of epistemic norms. (P\&C 1999, 139-40)

I can accept all of this. For norm externalism as I understand it is not itself ameliorative or regulative; it's theoretical (cf. P\&C 1999, 141). Norm externalism in my hands does not set out to criticize and correct our epistemic norms on the basis of considerations of external reliability. Rather it explains why some of our belief-forming processes lead to justified beliefs, and why some do not. Pollock and Cruz's reasonable point about the self-correcting nature of our norms does not touch the view I have advanced. 
in achieving practical success. Is this a way of resurrecting reliabilism? ... The upshot is it is not clear how the pursuit of true belief enters into the evaluation of cognitive architectures. It seems clear that truth is often a good thing, but not all truth are equally desirable, nor are all falsehood equally undesirable ... . In particular, any attempt to resurrect reliabilism [by appeal to truth in assisting the fulfillment of practical goals like survival] is doomed to failure. (1999, 175-6, emphasis added)

From the point of view of evolutionary theory and natural selection, truth is not the external ground by which we judge 'epistemic' norms; rather practical success is the external ground by which we judge our inner psychological belief-forming processes. Hence norm externalism cannot be correct, for the defining feature of norm externalism is the appeal to truth as the external criterion by which we judge 'epistemic norms.' Any appeal to evolutionary considerations like mine is thus 'doomed to failure.'

This kind of argument is commonplace. Here are two similar arguments. 'Natural selection only cares about survival, not truth. Hence truth is not the function of any evolved trait, let alone belief-formation.' And 'our brain evolved to assist feeding, fleeing, fighting and reproducing. Since truth is not one of the four Fs, discovering the truth is not the evolved function of cognition.' No belief forming process can have forming true beliefs reliably as a function.

Though commonplace, these arguments make a common mistake: they falsely assume that belief-forming processes can have but one function. I've italicized the offending assumption in the passage from Pollock and Cruz, and in the two arguments just rehearsed. What the view of justification sketched above requires is that reliability be $a$ function of (some of) our belief-forming processes. Truth and reliability does not have to be the one and only, or even the 'ultimate,' function of a beliefforming process for forming true beliefs reliably to be a function of the process. If reliability is a function, then normal functioning is a success constitutively associated with promoting truth and avoiding error.

Could our belief forming processes have more than one function? Of course. Few evolved traits have but one. Functional items often have a plurality of etiological functions. One item may be selected to do many things. Take the tongue. The tongue is for eating and talking. And by eating, the tongue assists in fulfilling other functions, such as getting enough food and nutrients into the bloodstream so as to nourish other parts of the body, so as to remain healthy and fit, so as to assist in dealing with the creature's natural habitat, so as to find more food, avoid predators, find mates, and so on, so as to live long enough to reproduce. The heart pumps blood, and in so doing carries oxygen to the brain, which helps cognition, which helps avoiding predators and finding mates, which helps the organism live long enough to reproduce. How 
could any of this show that pumping blood is not $a$ function of the heart?

Perception contributes to finding food, fleeing predators, fighting rivals, and meeting potential mates by reliably representing features of our external environment. Forming true beliefs reliably is $a$ function of our many of our belief forming systems. 'Epistemic' cognition provides a 'factual' background for practical cognition by reliably providing accurate information.

I can happily agree with Pollock and Cruz that 'the ultimate objective' of belief formation is not truth, but without agreeing that truth plays no role at all in distinguishing between belief forming processes that confer justification, and those that do not. And once they appreciate that from a 'naturalistic' evolutionary point of view that beliefforming processes can have more than one function, and that reliability can be one of them, they have no reason not to accept the account I have sketched. Evaluating cognitive architectures in terms of practical success as 'the ultimate aim' doesn't doom the very idea that justification aims at truth.

Pollock and Cruz can and should accept that (a kind or source of) justification consists in normal functioning when the process has reliability as a function. Justification aims at truth, and they can and should think so too. ${ }^{11}$

Received: January 2009

Revised: June 2010

\section{References}

Audi, R. 1988. 'Justification, Truth, and Reliability.' Philosophy and Phenomenological Research 14: 1-29.

2001. The Architecture of Reason. New York: Oxford University Press.

Bergman, M. 2006. Justification without Awareness. New York: Oxford University Press.

Buller, D., ed. 1999. Function, Selection, and Design. Stony Brook: SUNY Press.

Burge, T. 2003. 'Perceptual Entitlement.' Philosophy and Phenomenological Research 67: 50348.

11 I am grateful to the two referees for their very helpful comments. They caught a number of errors, and prompted substantial improvements. 
Burge, T. 2007. Foundations of Mind: Philosophical Essays, volume 2. Oxford: Clarendon Press.

Burge, T. 2010. Origins of Objectivity. Oxford: Oxford University Press.

Cruz, J. and Pollock, J. 2004. 'The Chimerical Appeal of Epistemic Externalism.' In The Externalist Challenge, R. Schantz, ed. Berlin: De Gruyter.

Goldman, A. 1986. Epistemology and Cognition. Cambridge: Harvard University Press.

Graham, P.J. 2010. 'Testimonial Entitlement and the Function of Comprehension.' In Social Epistemology, A. Haddock, A. Millar, and D. Pritchard, eds. Oxford: Oxford University Press.

. 2011. 'Intelligent Design and Selective History: Two Sources of Purpose and Plan.' Oxford Studies in Philosophy of Religion.

forthcoming. 'Epistemic Entitlement.' Noûs.

. manuscript. 'Perceptual Entitlement and Natural Norms.'

Landesman, C. 2002. Skepticism: The Central Issues. Oxford: Blackwell Publishers.

Millikan, R.1984. Language, Thought, and Other Biological Categories. Cambridge: The MIT Press.

Plantinga, A. 1993. Warrant: The Current Debate. New York: Oxford University Press.

Pollock, J. 1999. ‘Procedural Epistemology.' In The Blackwell Guide to Epistemology, J. Greco and E. Sosa, eds. Cambridge: Blackwell Publishers.

Pollock, J. and Cruz, J. 1999. Contemporary Theories of Knowledge, 2nd ed. Lanham, MD: Rowman \& Littlefield.

Schmitt, F. 1992. Knowledge and Belief. New York: Routledge.

Sosa, E. 2003. Epistemic Justification (with Laurence BonJour). Oxford: Blackwell Publishers.

Wright, L. 1973. 'Functions.' The Philosophical Review 82: 139-68. 
72 Peter J. Graham 